\title{
LEVER SIGN TEST FOR CHRONIC ACL INJURY: A COMPARISON WITH LACHMAN AND ANTERIOR DRAWER TESTS
}

\section{TESTE DA ALAVANCA PARA LESÃO CRÔNICA DO LCA: COMPARAÇÃO COM OS TESTES DE LACHMAN E GAVETA ANTERIOR}

\author{
Marcel Faraco Sobrado $0^{1,2}$ (1), Marcelo Batista Bonadio ${ }^{1}$ (i), Gabriel Fernandes Ribeiro ${ }^{1}$ (i), Pedro Nogueira Giglio ${ }^{1}$ (i), \\ Camilo Partezani Helito ${ }^{1,2}$ (i), Marco Kawamura Demange ${ }^{1}$ (1)
}

1. Universidade de São Paulo, Faculty of Medicine, Hospital das Clínicas, Institute of Orthopedics and Traumatology, HC-FMUSP, Grupo de Joelho, São Paulo, SP, Brazil. 2. Hospital Sírio-Libanês, São Paulo, SP, Brazil.

\section{ABSTRACT}

Objective: This study aims to evaluate the sensitivity and specificity of the lever sign test in patients with and without chronic Anterior Cruciate Ligament (ACL) injuries in an outpatient setting and the inter-examiner agreement of surgeons with different levels of experience. Methods: 72 consecutive patients with a history of previous knee sprains were included. The Lachman, anterior drawer, and Lever Sign tests were performed for all subjects in a randomized order by three blinded raters with different levels of experience. Sensitivity, specificity, positive predictive value, negative predictive value, and inter-rater agreement were estimated for all tests. Results: Among the 72 patients, the prevalence of $\mathrm{ACL}$ injuries was $54 \%$. The lever test showed sensitivity of $64.1 \%$ (95\% $\mathrm{Cl} 0.47-0.78)$ and specificity of $100 \%(95 \% \mathrm{Cl} 0.87-1.00)$ for the senior examiner. For the less experienced examiner the sensitivity was $51.8 \%$ and the specificity was $93.7 \%$. Positive predictive values (PPV) and negative predictive values (NPV) were $100 \%$ and $70.2 \%$, respectively. Conclusion: Lever Sign test shows to be a maneuver of easy execution, with $100 \%$ specificity and $100 \%$ PPV. Moderate agreement between experienced examiners and low agreement among experienced and inexperienced examiners was found. This test may play a role as an auxiliary maneuver. Level of Evidence I, Diagnostic Studies - Investigating a Diagnostic Test.

Keywords: Anterior Cruciate Ligament. Anterior Cruciate Ligament Injuries. Knee Joint. Joint Instability.

\section{RESUMO}

Objetivo: O objetivo deste estudo foi avaliar a sensibilidade e a especificidade do teste da alavanca em pacientes ambulatoriais com e sem lesões crônicas do LCA e a concordância entre examinadores com diferentes níveis de experiência. Métodos: Setenta e dois pacientes consecutivos com histórico de entorse de joelho foram incluídos. O teste de lachman, gaveta anterior e teste de alavanca foram realizados para todos os indivíduos em ordem randomizada por 3 examinadores cegados com diferentes níveis de experiência. Sensibilidade, especificidade, valor preditivo positivo, valor preditivo negativo e concordância interavaliadores foram calculados para todos os testes. Resultados: Entre os 72 pacientes, a prevalência de lesões do LCA foi de 54\%. O teste da alavanca mostrou sensibilidade de $64,1 \%$ (IC95\% 0,47-0,78) e especificidade de 100\% (IC95\% $0,87-1,00)$ para o examinador sênior. Para o examinador menos experiente, a sensibilidade foi de 51,8\% e a especificidade, de 93,7\%. Valores preditivos positivos (VPP) e valores preditivos negativos (VPN) foram de 100\% e 70,2\%, respectivamente. Conclusão: O teste da alavanca mostra ser uma manobra de fácil execução, com $100 \%$ de especificidade e $100 \%$ de PPV. Foi encontrada concordância moderada entre examinadores experientes e baixa concordância entre examinadores experientes e inexperientes. Este teste pode desempenhar um papel como uma manobra adjuvante. Nível de Evidência I, Estudos Diagnósticos - Investigação de um Exame para Diagnóstico.

Descritores: Ligamento Cruzado Anterior. Lesões do Ligamento Cruzado Anterior. Articulação do Joelho. Instabilidade Articular.

Citation: Sobrado MF, Bonadio MB, Ribeiro GF, Giglio PN, Helito CP, Demange MK. Lever sign test for chronic ACL injury: a comparison with Lachman and anterior drawer tests. Acta Ortop Bras. [online]. 2021;29(3):132-136. Available from URL: http://www.scielo.br/aob.

\section{INTRODUCTION}

Anterior cruciate ligament (ACL) injuries are the most common ligament injuries of the knee. ${ }^{1}$ Diagnosis is made based on history, physical examination and confirmed by magnetic resonance imaging (MRI) and diagnostic arthroscopy. ${ }^{2}$
The most frequently employed physical examination tests are the Lachman, the anterior drawer, and the pivot shift, which have high sensitivity and specificity. Among the three tests, the Lachman test is accepted as the most sensitive (85-96\%). ${ }^{3,4}$ However, examiner experience, patient's body habitus and the presence of knee effusion and pain ${ }^{5,6}$ can impair the execution of the tests. ${ }^{7}$ Some series

All authors declare no potential conflict of interest related to this article.

The study was conducted at Universidade de São Paulo, Faculty of Medicine, Hospital das Clínicas, Institute of Orthopedics and Traumatology.

Correspondence: Marcel Faraco Sobrado. Rua Dr. Ovídio Pires de Campos, 333, Cerqueira Cesar, São Paulo, SP, Brazil, 05403010. marcelfs@gmail.com 
have shown up to $74 \%$ of failure in clinical diagnosis of acute $\mathrm{ACL}$ injuries among emergency physicians. ${ }^{8}$ The significance of the examiner proficiency is further shown by a study in which primary care physicians identified correctly only $62 \%$ of chronic ACL injuries, in comparison to $94 \%$ for orthopedic surgeons. ${ }^{5}$

In 2016, Lelli et al. ${ }^{9}$ described a new maneuver for the diagnosis of ACL injuries, called the Lever Sign test. They reported 100\% sensitivity and $100 \%$ specificity for both acute and chronic injuries, even in patients with large muscle mass and obese. The test does not reproduce the rapid translational movements between the tibia and the femur, so it might induce less pain and resistance by the patient. Also, the objective assessment of the test positivity is reported to be easier than for the traditional tests, especially for inexperienced examiners. ${ }^{9}$

Other authors have investigated the Lever Sign test and found lower sensitivity (38-98\%) $)^{10,11}$ and specificity (72-100\%). ${ }^{10,12}$ Studies are yet to be able to reproduce the results published by Lelli et al. ${ }^{9}$ The fact that no study has specifically evaluated the claim that the test might be easier to perform and therefore more accurate for inexperienced or non-specialist examiners is especially interesting. Moreover, its performance has not been previously tested in chronic injury settings.

This study aims to evaluate the performance of the Lever Sign test for chronic ACL injury and to evaluate inter-rater agreement between two experienced examiners and between an experienced and an inexperienced examiner, in comparison to the Lachman and the Anterior Drawer tests.

\section{MATERIALS AND METHODS}

The study was conducted from August 2017 to June 2018 in an orthopedic department of a tertiary hospital after approval by the institutional ethics review board.

In total, 72 consecutive patients were evaluated at the first outpatient visit in the institution. All patients had a history of knee sprain for more than one month and had been referred for evaluation.

Inclusion criteria were age between 18 and 50 years, history of knee sprain for at least 1 month without previous knee surgeries and an available MRI to confirm the diagnosis. ACL injury at MRI was defined as a complete ligament rupture. Patients with other ligament tears, diagnosis of osteoarthritis, and bilateral ACL injuries were excluded. The Lachman, Anterior Drawer, and Lever Sign tests were performed in all patients by the main examiner, a knee surgery specialist, and these data were used to evaluate the tests performance. Furthermore, to evaluate inter-examiner agreement in different levels of examiner experience, the first 35 patients of the study were also examined by another experienced knee surgeon, and an inexperienced one (a first-year resident of the orthopedic program), with little previous physical examination experience in knee ligament injuries. The inexperienced examiner was instructed on the physical examination tests prior to the beginning of this study.

All examiners were blind to the diagnosis and other information about the patient or the results of the physical examination by the other examiners. The examined limb, defined as the limb of the patient's complaint, was indicated by the researcher responsible for compiling the data. This last researcher was also blinded for the MRI and clinical results. Because the physical examination tests are clinically performed in a comparative way, the evaluation of the contralateral side was allowed, but only the index side data was considered for analysis.

The tests were performed in the office, without anesthesia, and recorded as positive or negative after a bilateral comparative evaluation of each test. The order of the tests was randomized, using a previously generated list, which was concealed from the examiner until the test in order to avoid performance bias by the previous test result.
The Lever Sign test was performed as it was originally described. ${ }^{9}$ The patient was lying in the supine position with knees in extension on a rigid surface, the examiner stands beside the patient and places the closed fist under the proximal third of the posterior leg, generating a small knee flexion. With the other hand, it exerts a moderate force from anterior to posterior on the distal third of the patient's thigh. The test is considered positive when passive elevation of the heel does not occur in relation to the plane of the examination table. The heel rise makes the test negative and therefore the ACL is considered intact (Figure 1).

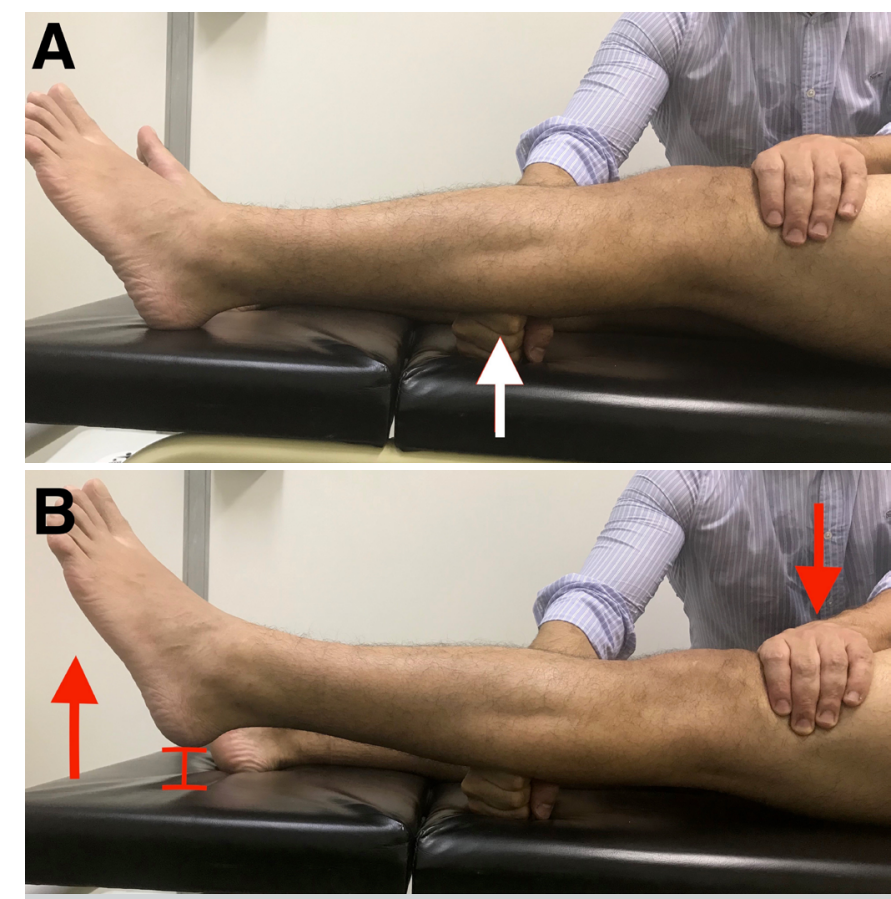

Figure 1. A: Closed fist is placed under the proximal third of the posterior leg in the resting position; B: A negative test is demonstrated.

\section{Data analysis}

For the Lachman, Anterior Drawer, and Lever Sign tests, the values of sensitivity, specificity, positive and negative predictive values were obtained for the main examiner and the resident examiner, with $95 \%$ confidence intervals $(95 \% \mathrm{Cl})$, using $\mathrm{MRI}$ as the gold standard diagnosis.

The inter-examiner agreement between the main examiner and the second experienced surgeon and between the main examiner and the orthopedic resident were evaluated with Cohen's Kappa coefficient. The agreement was interpreted according to McHugh: ${ }^{13}$ none (0-.20), minimal (.21-.39), weak (.40-.59), moderate (.60-.79), strong (80-.90), almost perfect (>.9).

For quantitatively comparing the discriminative ability of the tests, ROC (Receiver Operating Characteristic) curves were produced from the results obtained by the principal examiner. ${ }^{14,15}$ The use of ROC curves for binary diagnostic tests has been previously described. ${ }^{16}$ The areas under the curve obtained were compared between the diagnostic tests.

The sample size was defined based on the recommendations of Bujang and Adnan, ${ }^{17}$ considering an expected prevalence of $50 \%$ of ACL injuries among patients with history of knee sprains, ${ }^{18}$ expected sensitivity for the Lachman test of $90 \%$, and $80 \%$ power to demonstrate a $20 \%$ difference of the sensitivity of the tests. The calculated minimum sample was 62 participants, so we chose to enroll 72 patients for safety. 
Values of $\mathrm{p}<0.05$ and differences beyond $95 \% \mathrm{Cl}$ were considered statistically significant. Statistical software SPSS 22 (IBM Corp., NY, USA) and VassarStats (Richard Lowry, Vassar College, NY, USA) were used.

\section{RESULTS}

In total, 72 patients were included in the study, 49 men and 23 women, with a mean age of $33.2 \pm 8.6$ years. The prevalence of ACL injuries was $54 \%$ among all knee sprains, of which 39 had ACL rupture and 33 had no injury.

For the main examiner, the Lever Sign test sensitivity was $64.1 \%$ (95\% Cl 47-78\%), specificity was 100\% (95\% Cl 87-100\%), positive predictive value (PPV) was 100\% (95\% Cl 0.83-1.00), negative predictive value (NPV) was $70.2 \%(95 \% \mathrm{Cl} 0.55-0.82)$ and accuracy was $80.5 \%$.

The Lachman and Anterior Drawer test for the main examiner were, respectively, 94.8\% (95\% Cl 81-99\%) and 82.0\% (95\% Cl 65-91\%) sensitivity, 100.0\% (95\% Cl 87-100\%) and 84.8\% (95\% Cl 67-94\%) specificity, $100 \%$ (95\% Cl 88-100\%) and $86.4 \%$ (95\% Cl 70-94\%) PPV, 94.2\% (95\% Cl 79-99\%) and 80.0\% (95\% Cl 62-90\%) NPV, and $97.2 \%$ and $32.3 \%$ accuracy. Therefore, the Lachman test had a superior specificity to the Lever Sign test beyond the $95 \% \mathrm{Cl}$ (Table 1).

Table 1. Tests performance for the main examiner. 95\% confidence intervals in parentheses.

\begin{tabular}{c|c|c|c|c}
\hline Test & Sensitivity & Specificity & VPP & VPN \\
\hline \multirow{2}{*}{ Lever Sign } & $\begin{array}{c}64.1 \% \\
(47-78 \%)^{*}\end{array}$ & $\begin{array}{c}100 \% \\
(87-100 \%)\end{array}$ & $\begin{array}{c}100 \% \\
(83-100 \%)\end{array}$ & $\begin{array}{c}70.2 \% \\
(54-82 \%)\end{array}$ \\
\hline \multirow{2}{*}{ Lachman } & $94.8 \%$ & $100 \%$ & $100 \%$ & $94.2 \%$ \\
& $(81-99 \%)$ & $(87-100 \%)$ & $(88-100 \%)$ & $(79-99 \%)$ \\
\hline Anterior & $82.0 \%$ & $84.85 \%$ & $86.4 \%$ & $80 \%$ \\
drawer & $(65-91 \%)^{*}$ & $(67-94 \%)$ & $(70-94 \%)$ & $(62-90 \%)$ \\
\hline
\end{tabular}

*: statistically significant.

For the inexperienced examiner, the Lever Sign test percentages were 51.8\% (95\% Cl 32-70\%) sensitivity, 93.7\% (95\% Cl 67-99\%) specificity, 93.3\% (95\% Cl 66-99\%) PPV, 53.5\% (95\% Cl 34-71\%) NPV and $67.4 \%$ accuracy.

The Lachman and Anterior Drawer test for the inexperienced examiner presented, respectively, 66.6\% (95\% Cl 46-82\%) and 62.9\% (95\% Cl 42-79\%) sensitivity, 93.7\% (95\% Cl 67-99\%) and $93.7 \%$ (95\% Cl 67-99\%) specificity, 94.7\% (95\% Cl 71-99\%) and $94.4 \%$ (95\% Cl 70-99\%) PPV, 62.5\% (95\% Cl 40-80\%) and 60.0\% (95\% $\mathrm{Cl} 38-78 \%) \mathrm{NPV}$, and $76.4 \%$ and $74.4 \%$ accuracy.

The inter-examiner agreement by the Kappa coefficient between the main examiner and the second experienced examiner was 0.60 (moderate) for the Lever Sign ( $p=0.001), 0.92$ (almost perfect) for the Lachman test $(p<0.001)$, and 0.60 (moderate) for the Anterior Drawer test $(p=0.001)$ (Table 2$)$.

Table 2. Inter-rater agreement by the Kappa coefficient.

\begin{tabular}{c|c|c|c|c}
\hline & \multicolumn{4}{|c}{ Kappa coefficient } \\
\hline Test & $\begin{array}{c}\text { Main examiner vs } \\
\text { experienced examiner }\end{array}$ & $p$ & $\begin{array}{c}\text { Main examiner vs } \\
\text { inexperienced examiner }\end{array}$ & $p$ \\
\hline Lever Sign & $0.60(0.32-0.88)$ & 0.001 & $0.35(0.05-0.66)$ & 0.034 \\
\hline Lachman & $0.92(0.78-1.00)$ & $<0.001$ & $0.42(0.14-0.71)$ & 0.009 \\
\hline $\begin{array}{c}\text { Anterior } \\
\text { drawer }\end{array}$ & $0.60(0.31-0.88)$ & 0.001 & $0.34(0.02-0.66)$ & 0.052 \\
\hline
\end{tabular}

Values in parentheses are $95 \% \mathrm{Cl}$.
Between the main examiner and the inexperienced examiner, inter-examiner agreement by the Kappa coefficient was 0.35 (minimum) for the Lever Sign test ( $p=0.034), 0.42$ (weak) for the Lachman test ( $p=0.009$ ), and 0.34 (minimum) for the anterior drawer test ( $p=0.052)$ (Table 2$)$

The ROC curve was 0.974 in area under the curve (AUC) for the Lachman test, 0.834 for the anterior drawer test and 0.821 for the Lever Sign test (Figure 2 and Table 3). The Lachman test AUC was higher than the anterior drawer and Lever Sign tests $(p=0.008$ and 0.004 , respectively).

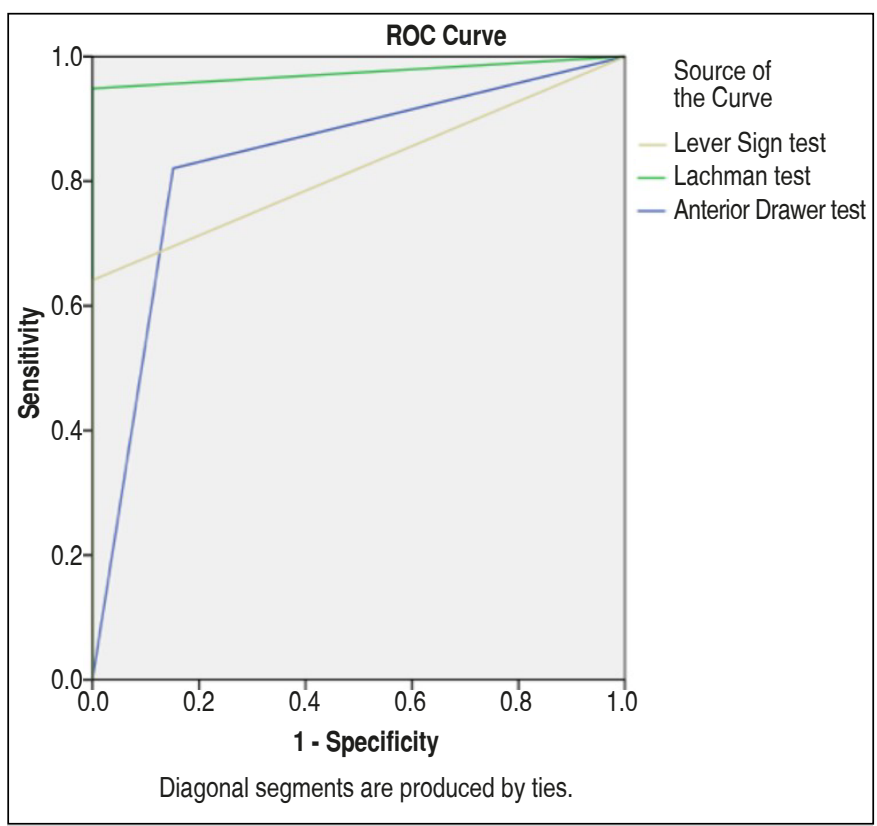

Figure 2. Receiver Operating Characteristic (ROC) curves of test maneuvers.

Table 3. Area under the curve (AUC) for Receiver Operating Characteristic (ROC) curves.

\begin{tabular}{c|c}
\hline Diagnostic test & AUC \\
\hline Lever Sign & $0.821 \star \dagger$ \\
\hline Anterior Drawer & $0.834^{*} \bullet$ \\
\hline Lachman & $0.974^{*} \dagger$
\end{tabular}

*: $p=0.008 ; \uparrow: p=0.004 ;: p=0.85$ (not significant)

\section{DISCUSSION}

The main finding of this study is that the Lever Sign test is a maneuver with $100 \%$ specificity and 100\% PPV despite not having a high sensitivity. It was less sensitive and less accurate than the Lachman test and presented moderate agreement among experienced examiners and a low agreement between an inexperienced and the experienced examiners.

Currently, physical examination tests are not always able to confirm ACL insufficiency, therefore there is great interest in the test described by Lelli et al., ${ }^{9}$ which was reported to achieve $100 \%$ sensitivity and specificity in their study.

Unfortunately, the test showed to have much higher accuracy in experienced examiners and should not be extrapolated as the gold standard for ACL injury to all emergency physicians or orthopedic surgeons who do not have a knee surgery or sports medicine background, as it was initially speculated. Our results were discordant with those reported by Jarbo et al., ${ }^{19}$ who found similar 
accuracy between undergraduate and senior staff, $84 \%$ and $88 \%$, respectively. In our study, the accuracy was proportional to the evaluator's experience, with $81.4 \%$ for the experience evaluator and $67.4 \%$ for the orthopedic resident.

Despite the high sensitivity of MRI for the ACL rupture diagnosis, ${ }^{20}$ it is often not readily available in the clinical or emergency scenario and physical examination is extremely valuable for the diagnosis of ligament injuries of the knee.

Regarding the original article of the maneuver, it should be mentioned that the author created the test and all studied patients already had the presumed diagnosis of the injury. The examiner was also not blinded. This may constitute a significant observer bias for the study.

Our study found a $64.10 \%$ combined sensitivity and $100 \%$ specificity, which is closer to the results obtained in recent studies. ${ }^{10-12,19-22}$ The main characteristic common to all studies to date that studied this maneuver is the high specificity despite a moderate sensitivity. In this context, this maneuver of easy execution becomes desirable when used in association with other propaedeutic exams, since a positive result is highly suggestive of an ACL injury. The maneuver must be performed on a rigid surface because when a softer and padded surface is used, we observed that the wrist under the leg sinks into the patient's bed and can change the test result. This influence of surface type on the positivity of the test has not been investigated and future studies may define the real importance of this factor.

Recently, other authors have investigated this maneuver and found divergent results of sensitivity and specificity: Jarbo et al. ${ }^{19} 63 \%$ and $90 \%$, Lichtenberg et al. ${ }^{12} 39 \%$ and $100 \%$, Mulligan et al. ${ }^{10} 38 \%$ and $72 \%$, Massey et al. ${ }^{21} 83 \%$ and $80 \%$, Deveci et al. ${ }^{11} 94-98 \%$ and Chong et al. ${ }^{22} 82-88 \%$ and $100 \%$, respectively.

Physical examination maneuvers are known to be insufficient in the diagnosis of ACL injuries depending on the examiner's experience ${ }^{5,23}$ and for acute scenarios, in which knee effusion and muscle spasms lead to lowed sensitivity values. ${ }^{4}$ Thus, our study included only chronic lesions and evaluators with different experience levels were tested. The prevalence of ACL injury in our study was 54\%, which is similar to the results found in the literature. ${ }^{24}$ In the present study, the examiners had not had contact with the Lever Sign maneuver prior to the assessments and all of them started the learning curve concomitantly.

It is noteworthy that the mechanism by which the Lever Sign test works is not well understood from a biomechanical point of view. The theory that the force directed at the thigh from anterior to posterior position would be transmitted by the ACL and would act as a Lever Sign for the tibia, surpassing the force of gravity and generating the heel elevation from the bed plane was not biomechanically validated. It is important to note that the Lever Sign test does not contemplate the ACL rotational restriction component and the possible involvement of knee anterolateral structures, which may decrease the accuracy for patients who present greater rotational instability than anterior translation. This occurs in patients with a more significant pivot shift than the Lachman and anterior drawer tests, as it has already been demonstrated in cases of partial injuries of the posterolateral ACL band. ${ }^{25}$ Thus, the Lever Sign test has a qualitative character and does not allow the quantification of translational or rotational instability. In this study, the behavior of the different functional bands in the ACL partial ruptures was not separately studied since all patients presented complete ligament rupture. The force to be applied to the thigh is also not well established and since it is not theoretically a comparative test to the contralateral limb, its positivity is based only on the heel elevation at the examination table and it is not known if the use of a greater force could elevate the limb even in the absence of ACL injury. We thus believe that the maneuver should be performed in a comparative bilateral way in order to establish a minimum adequate force to acquire the elevation of the non-affected limb and to define the response pattern for that individual. However, in our study this concern was not verified, and the test presented excellent specificity. In the present study the applied force was not measured or standardized, but the same examiner applied similar force intensity and did it comparatively bilaterally, as is usually done in the outpatient physical examination for the Lachman and anterior drawer tests.

This study presents some limitations, such as the fact that the evaluations were performed only with non-anesthetized patients. It is known that the values of sensitivity, specificity and accuracy increase with the anesthetized patient, ${ }^{6}$ but the purpose of the study was to evaluate the diagnosis in the clinical context of the office or emergency room with an awake patient. It is also noteworthy that the gold standard to determine the injury positivity was magnetic resonance imaging evaluated by experienced musculoskeletal radiologists, which, although present high sensitivity and specificity values and $93.5 \%$ accuracy, can be cited as a possible limitation. ${ }^{2}$ Another limitation is that the first 30 patients were evaluated sequentially by the 3 examiners, for 9 total maneuvers performed on each patient, which may increase discomfort and promote some degree of muscle spasm, altering the results.

Thus, the Lever Sign tests proved to be an easy maneuver with moderate agreement between experienced examiners and low agreement among experienced and inexperienced examiner. This test has a role as an adjuvant maneuver, but not isolated for the diagnosis of ACL ruptures.

\section{CONCLUSION}

Lever Sign test was shown to be a maneuver of easy execution, with $100 \%$ specificity and $100 \%$ positive predictive value. Moderate agreement between experienced examiners and low agreement between experienced and inexperienced examiners was found. This test may play a role as an adjuvant maneuver.

AUTHORS' CONTRIBUTIONS: Each author contributed individually and significantly to the development of this article. MFS: intellectual concept of the study, performed test, conducted the bibliographic research, evaluated and interpreted the data collected, and wrote the manuscript; MBB: intellectual concept of the study, performed physical examination, conducted the bibliographic research, evaluated and interpreted the data collected, and wrote the manuscript; GFR: collected data, performed physical examination, drafted the manuscript; PNG: intellectual concept of the study, statistical analysis, drafted and revised the manuscript; $\mathrm{CPH}$ : analyzed the data collected, performed the final revision of the manuscript, and also contributed to the intellectual concept of the study; MKD: analyzed the data collected, performed the final revision of the manuscript, and also contributed to the intellectual concept of the study.

\section{REFERENCES}

1. Prodromos CC, Han Y, Rogowski J, Joyce B, Shi K. A meta-analysis of the incidence of anterior cruciate ligament tears as a function of gender, sport, and a knee injury-reduction regimen. Arthroscopy. 2007;23(12):1320-5.e6.

2. Crawford R, Walley G, Bridgman S, Maffulli N. Magnetic resonance imaging versus arthroscopy in the diagnosis of knee pathology, concentrating on meniscal lesions and ACL tears: a systematic review. Br Med Bull. 2007;84:5-23.
3. Benjaminse A, Gokeler A, van der Schans CP. Clinical diagnosis of an anterior cruciate ligament rupture: a meta-analysis. J Orthop Sports Phys Ther. 2006;36(5):267-88.

4. Leblanc MC, Kowalczuk M, Andruszkiewicz N, Simunovic N, Farrokhyar F Turnbull TL, et al. Diagnostic accuracy of physical examination for anterior knee instability: a systematic review. Knee Surg Sports Traumatol Arthrosc. 2015;23(10):2805-13.

5. Geraets SEW, Meuffels DE, van Meer BL, Breedveldt Boer HP, Bierma-Zeinstra SMA, Reijman M. Diagnostic value of medical history and physical examination of 
anterior cruciate ligament injury: comparison between primary care physician and orthopaedic surgeon. Knee Surg Sports Traumatol Arthrosc. 2015;23(4):968-74.

6. van Eck CF, van den Bekerom MPJ, Fu FH, Poolman RW, Kerkhoffs GMMJ Methods to diagnose acute anterior cruciate ligament rupture: a meta-analysis of physical examinations with and without anaesthesia. Knee Surg Sports Traumatol Arthrosc. 2013;21(8):1895-903.

7. Mulligan EP, Harwell JL, Robertson WJ. Reliability and diagnostic accuracy of the Lachman test performed in a prone position. J Orthop Sports Phys Ther. 2011;41(10):749-57.

8. Guillodo Y, Rannou N, Dubrana F, Lefèvre C, Saraux A. Diagnosis of anterior cruciate ligament rupture in an emergency department. J Trauma. 2008;65(5):1078-82.

9. Lelli A, Di Turi RP, Spenciner DB, Dòmini M. The "Lever Sign": a new clinical test for the diagnosis of anterior cruciate ligament rupture. Knee Surg Sports Traumatol Arthrosc. 2016;24(9):2794-7.

10. Mulligan EP, Anderson A, Watson S, Dimeff RJ. The diagnostic accuracy of the lever sign for detecting anterior cruciate ligament injury. Int J Sports Phys Ther. 2017;12(7):1057-67.

11. Deveci A, Cankaya D, Yilmaz S, Özdemir G, Arslantas E, Bozkurt M. The arthroscopical and radiological corelation of lever sign test for the diagnosis of anterior cruciate ligament rupture. Springerplus. 2015;4:830.

12. Lichtenberg MC, Koster CH, Teunissen LPJ, Oosterveld FGJ, Harmsen AMK, Haverkamp D, et al. Does the Lever Sign Test Have Added Value for Diagnosing Anterior Cruciate Ligament Ruptures? Orthop J Sports Med. 2018;6(3):2325967118759631.

13. McHugh ML. Interrater reliability: the kappa statistic. Biochem Med. 2012;22(3):276-82.

14. Hanley JA, McNeil BJ. The meaning and use of the area under a receiver operating characteristic (ROC) curve. Radiology. 1982;143(1):29-36.

15. Metz CE. Basic principles of ROC analysis. Semin Nucl Med. 1978;8(4):283-98.
16. Cantor SB, Kattan MW. Determining the area under the ROC curve for a binary diagnostic test. Med Decis Making. 2000;20(4):468-70.

17. Bujang MA, Adnan TH. Requirements for Minimum Sample Size for Sensitivity and Specificity Analysis. J Clin Diagn Res. 2016;10(10):YE01-6.

18. Olsson O, Isacsson A, Englund M, Frobell RB. Epidemiology of intra- and peri-articular structural injuries in traumatic knee joint hemarthrosis - data from 1145 consecutive knees with subacute MRI. Osteoarthritis Cartilage. 2016;24(11):1890-7.

19. Jarbo KA, Hartigan DE, Scott KL, Patel KA, Chhabra A. Accuracy of the Lever Sign Test in the Diagnosis of Anterior Cruciate Ligament Injuries. Orthop J Sports Med. 2017;5(10):2325967117729809.

20. Fischer SP, Fox JM, Del Pizzo W, Friedman MJ, Snyder SJ, Ferkel RD. Accuracy of diagnoses from magnetic resonance imaging of the knee. A multi-center analysis of one thousand and fourteen patients. J Bone Joint Surg Am. 1991;73(1):2-10.

21. Massey PA, Harris JD, Winston LA, Lintner DM, Delgado DA, McCulloch PC Critical Analysis of the Lever Test for Diagnosis of Anterior Cruciate Ligament Insufficiency. Arthroscopy. 2017;33(8):1560-6.

22. Chong AC, Whitetree C, Priddy MC, Zimmerman PR, Haeder PR, Prohaska DJ. Evaluating Different Clinical Diagnosis of Anterior Cruciate Ligament Ruptures In Providers with Different Training Backgrounds. lowa Orthop J. 2017;37:71-9.

23. Wagemakers HP, Luijsterburg PA, Boks SS, Heintjes EM, Berger MY, Verhaar $\mathrm{JA}$, et al. Diagnostic accuracy of history taking and physical examination for assessing anterior cruciate ligament lesions of the knee in primary care. Arch Phys Med Rehabil. 2010;91(9):1452-9.

24. Frobell RB, Lohmander LS, Roos HP. Acute rotational trauma to the knee: poo agreement between clinical assessment and magnetic resonance imaging findings. Scand J Med Sci Sports. 2007;17(2):109-14.

25. Siebold R, Fu FH. Assessment and augmentation of symptomatic anteromedial or posterolateral bundle tears of the anterior cruciate ligament. Arthroscopy. 2008;24(11):1289-98. 